\title{
Inflammatory Bowel Disease and Quality of Life in King Abdulaziz Medical City
}

\author{
Fahad A. Alowais', Yazeed A. Alferayan², Rayed M. Aljehani1 \\ ${ }^{1}$ College of Medicine, King Saud Bin Abdulaziz University for Health Sciences, Riyadh, Saudi Arabia \\ ${ }^{2}$ King Saud Bin Abdulaziz University for Health Sciences, King Abdulaziz Medical City, Riyadh, Saudi Arabia \\ Email: f.a.h.a.d@live.com
}

Received 21 December 2015; accepted 20 January 2016; published 25 January 2016

Copyright (C) 2016 by authors and Scientific Research Publishing Inc.

This work is licensed under the Creative Commons Attribution International License (CC BY).

http://creativecommons.org/licenses/by/4.0/

(c) (i) Open Access

\section{Abstract}

Background: Health Related Quality of life (HRQOL) assessment is an important outcome to measure Inflammatory Bowel Disease (IBD). The aim of this study is to evaluate the effects of IBD in patients' quality of life in King Abdulaziz Medical City, Riyadh. Methods: This is a cohort study of 32 patients with IBD who were given the Inflammatory Bowel Disease Questionnaire (IBDQ) in the outpatient clinic at King Abdulaziz Medical City, Riyadh during the study period of three months in 2014. Results: In a comparison between patients who have Ulcerative Colitis (UC) in contrast to Crohn's Disease (CD), we found that the mean score for the IBDQ were 170.94 and 149.69 respectively. The worst score was 65 in CD and the highest was 224 in UC. Comparing the subdivisions of the IBDQ it was found that the bowel and systemic domains were affected mostly by the disease. Conclusion: Inflammatory bowel disease has a major impact on HRQOL of patients in different aspects. CD group has worse HRQOL than UC group. The total score was impacted mostly by the systemic and bowel domains in the IBDQ. Saudi patients were more affected by the disease compared to other countries.

\section{Keywords}

HRQOL, Inflammatory Bowel Diseases, IBDQ, Crohn's Disease, Ulcerative Colitis

\section{Introduction}

Inflammatory bowel disease (IBD) is a chronic progressive inflammation of the intestines [1]. IBD includes ulcerative colitis (UC), Crohn's disease (CD) [2]. In Crohn's disease the inflammation can affect any part of the gastrointestinal tract (GIT), although the terminal part is most commonly involved. Crohn's inflammation can involve the full thickness of the bowel. In UC the disease is limited to the colon [3]. The peak age of onset is 15 
to 30 years [1]. The incidence of IBD in Saudi Arabia has increased over the last 3 decades. From 1983 to 2002, the incidence of IBD increased from 0.32 to 1.66 per 100,000 [4]. The incidence rate worldwide for CD ranges from 5.0 to 12.7 per 100,000 and for UC ranges from 6.3 to 24.3 per 100,000 [5].

The major symptoms of IBD are diarrhea, abdominal pain, GI bleeding, weight loss, nausea and vomiting. Extra intestinal involvement includes skin lesions, arthritis, as well as iritis. Patients are worried about losing bowel control in public places or emitting malodors. They also feel unwell and have to constantly take medications, which might cause them to suffer from abdominal pain. Females may experience dyspareunia due to pelvic disease and males may have impotence [6]-[9]. All of these symptoms have significant physical and psychosocial impact on the patient's quality of life.

The diagnosis is made based on clinical features, endoscopic findings, radiology and in some cases serology. Histology is also needed to help differentiate UC and CD from other forms of colitis and ileitis [10]-[12].

The main goal in the management of IBD is to induce remission and prevent relapse. Treatment methods may include treatment with steroids, long term immunomodulators, and the newer anti-tumor necrosis factor drugs. Refractory cases may require surgery [13] [14].

Health assessment for patients with IBD usually focuses only on physical and lab findings, but it does not reflect the patients themselves. So, we need a more subjective way to evaluate the patients. It shows its importance when we are dealing with such a chronic disease, where the main goal of the treatment is to improve the patient's symptoms and HRQOL.

It is very important that we put an emphasis on the patients' quality of life and to include it in the follow up of the patients. There have been some studies indicating that there has been a lack of communication between the patients and their physicians when it comes to the quality of life as most of them report that their physicians don't ask about how the disease affects their quality of life. Patients with IBD also indicated that their symptoms severity hindered them from enjoying their hobbies and affected their job performance.

Also there was direct correlation between the patients' quality of life and disease activity [15]. This emphasizes the importance of the patients' disease activity and psychological functioning and quality of life. Usually the patients who had active disease had an increased distress, stress, anxiety and well being with a lower quality of life score compared to those who had inactive disease [16]. In addition, patients who had IBD had mild to moderate disability while a minority needed financial support. This indicates that the quality of life is highly important in the patients' condition as they might not be able to perform their work and need financial assistance [17].

There are many different HRQOL indexes such as the inflammatory bowel disease questionnaire (IBDQ) which showed a strong correlation between a better well being and reduced use of health services

By measuring the HRQOL in IBD patients we will have a comprehensive knowledge about how the disease affects the patients' quality of life. In the long term the disease process, symptoms, complications, as well as management itself affect the patients' quality of life and activity. The patients are under considerable stress and may also suffer from psychosocial problems.

The aim of the study is to measure the quality of life in IBD patients in King Abdulaziz Medical City (KAMC).

\section{Methodology}

\subsection{Participants}

The participants of this study were recruited from a random group of patients whom were diagnosed with IBD and presented to the outpatient clinic at King Abdulaziz Medical City, Riyadh, Saudi Arabia. The inclusion criteria were patients who had UC or CD and were under the treatment for the disease. The diagnosis was done based on clinical, endoscopic, radiological and histological criteria. Approval from institutional review board was obtained and all patients gave prior informed consent. A total of 32 patients (16 with UC and 16 with CD) matched the inclusion criteria.

\subsection{Assessment of HRQOL}

HRQOL was assessed by the use of a disease specific questionnaire, which was IBDQ. IBDQ was validated and translated into Arabic language previously. It is the most common used questionnaire to assess the HRQOL in IBD patients worldwide. IBDQ has shown to have adequate validity and reliability in different languages and cultures. IBDQ score has been shown to be highly correlated with the disease state whether in remission or re- 
lapse. The IBDQ contains 32 questions that are classified into four main domains: bowel symptoms (10 questions), systemic symptoms (5 questions), social impairment (5 questions) and emotional function (12 questions) [18]-[20]. The options for each question are graded from 1 to 7 , where 1 is indicates the worst symptoms and 7 as the best symptoms. The total score ranges from 32 to 224 the higher score indicates a better HRQOL and a lower score indicates poorer HRQOL.

\subsection{Analysis}

Patients' demographics were obtained including age and gender. Descriptive data was reported as mean, standard deviation and. The comparison between UC and CD was made by chi-squared test and t-test. The comparison between the two groups depended on the total of the IBDQ scores and the four domains of the IBDQ where a P-value $\leq 0.05$ was considered as significant result. Patients with higher score had a better QOL. All analysis was done using the IBM SPSS statistics software version 20.0 (SPSS, Inc., Chicago, IL).

\section{Results}

The study included a total number of 32 patients (16 UC, 16 CD). The majority of the study subjects were male 20 (63\%), females were $12(37 \%)$. The mean age of the total sample was $(34.28+16.71)$ with the youngest patient being 18 and the oldest being 71 . The mean weight for all the patients was $(66.78+20.50)$, while the mean BMI was $(25.04+7.18)$. The mean duration since diagnosis was $(4.84+2.88)$. They were divided into two groups for the sake of comparison; Group 1 included 16 patients who were diagnosed with Crohn's disease and group 2 included 16 patients who were diagnosed with ulcerative colitis (Table 1).

The duration of the disease was divided into three groups: group A included those who had the disease for less than 1 year, group $B$ between one year and 5 years and group $C$ who had the disease for more than 5 years. The mean of each group was $(168.80+39.66)$ for group A, $(143.53+45.39)$ for group B and $(177.75+34.72)$ for group $\mathrm{C}$. There was no significant difference regarding HRQOL between the 3 duration groups $(\mathrm{P}>0.05)$ (Table 2).

Most of the study subjects in group 1 were young with a mean of $(25.75+10.49)$, while in group 2 the mean was higher $(42.81+17.66)$ with $(\mathrm{P}=0.002)$ which was very significant. In group 1 the mean weight was (59.88 $+19.53)$ while in group $2(73.69+19.63)(\mathrm{P}=0.055)$. The BMI for group 2 was higher than group 1 with the mean BMI being $(27.78+6.54)$ and $(22.31+6.91)$ respectively with $(\mathrm{P}=0.029)$ (Table 1$)$.

The mean score of IBDQ in the two groups of patients was (160.31 \pm 42.74$)$ and ranged from (65 to 224), with a higher mean that was found in group $2(170.94 \pm 41.76)$ compared to $(149.69 \pm 42.31)$ in group 1 with a (p-value $=0.163$ ) indicating no statistical significance (Table 3$)$.

In the comparison of the four domains of the IBDQ it was found that the mean for the bowel domain for group 1 was $(46.94+12.66)$ and in group $2(52.25+14.92)(P=0.286)$. In the systemic domain the mean for group 1 was $(20.75+7.62)$ and in group2 $(25.13+6.88)(p=0.099)$. In the emotional domain also there was no significant difference between the two groups: group $1(51.13+20.16)$, group $2(63.75+16.04)(P=0.059)$. In the social domain there was a significant difference between both groups where group 2 reported a higher mean $(26.31+7.24)$ compared to group $1(19.56 \pm 9.83)(P-v a l u e=0.035)($ Table 3$)$.

Table 1. Demographics (mean \pm SD), p-value.

\begin{tabular}{ccccc}
\hline & $(\mathrm{CD}+\mathrm{UC})$ & $\mathrm{CD}$ & UC & P-value \\
\hline No. of patients & 32 & 16 & 16 & $0.002^{*}$ \\
Age & $34.28+16.71$ & $25.75+10.49$ & $42.81+17.66$ & \\
Gender & & & & 0.055 \\
Male & $20(63 \%)$ & & $73.69+19.63$ & $0.029 *$ \\
Female & $12(37 \%)$ & $59.88+19.53$ & $27.78+6.54$ & 0.056 \\
Weight & $66.78+20.50$ & $22.31+6.91$ & $5.81+3.03$ & \\
BMI & $25.04+7.18$ & $3.87+2.44$ & & \\
Duration & $4.84+2.88$ & & & \\
\hline
\end{tabular}

*Statistical significant at $\mathrm{P}<0.05$. 
Table 2. Disease duration and IBDQ total scores (mean \pm SD), P-value.

\begin{tabular}{ccc}
\hline & Total score IBDQ & P-value \\
\hline Group A & $168.80+39.66$ & \\
Group B & $143.53+45.39$ & $\mathbf{0 . 1 0 3}$ \\
Group C & $177.75+34.72$ & \\
\hline
\end{tabular}

Table 3. Total and subdivisions of IBDQ scores (mean \pm SD), P-value.

\begin{tabular}{ccccc}
\hline & $(\mathrm{CD}+\mathrm{UC})$ & $\mathrm{CD}$ & $\mathrm{UC}$ & P-value \\
\hline Bowel & $49.59 \pm 13.87$ & $46.94 \pm 12.66$ & $52.25 \pm 14.92$ & 0.286 \\
Systemic & $22.94 \pm 7.48$ & $20.75 \pm 7.62$ & $25.13 \pm 6.88$ & 0.099 \\
Emotional & $57.44 \pm 19.03$ & $51.13 \pm 20.16$ & $63.75 \pm 16.04$ & 0.059 \\
Social & $22.94 \pm 9.16$ & $19.56 \pm 9.83$ & $26.31 \pm 7.24$ & $0.035^{*}$ \\
Total & $160.31 \pm 42.74$ & $149.69 \pm 42.31$ & $170.94 \pm 41.76$ & 0.163 \\
\hline
\end{tabular}

*Statistical significant at $(\mathrm{p}<0.05)$.

\section{Discussion}

IBD is a chronic disease that has a significant impact on patients' quality of life and daily activity. So the assessment of patients HRQOL is an important tool for health practitioners to measure the patients' satisfaction and the effect of this chronic disease on their quality of life.

A similar result to our study regarding the age at diagnosis was found in a study conducted in North America, which showed a difference in the age at diagnosis between both groups. It showed the mean age at diagnosis observed in Crohn's disease was lower by 5 to 10 years when compared to ulcerative colitis [21].

As expected the weight in Crohn's patients was lower than ulcerative colitis patients, which might be due to more weight loss in Crohn's disease patients as they tend to have more malabsorbtion and feel better when they do not eat [22].

In the assessment of patients' HRQOL, it showed that in our population the results were considerably lower than the other population when we compared the total and the four domains of the IBDQ (Table 3). The IBDQ total score and its domains compared to previous HRQOL assessment studies in other countries (Netherlands, England and Greece) our population total score was lower than Han et al and Athansions G et al. and was higher compared to De Boer et al which was the lowest between the four studies [23]-[25]. These variations might be related to the cultural understanding towards the disease and the extent of social support between different countries. Disease behavior and the degree of response to treatment might be affected by the different genetic background and environmental factors. In general our total score for IBDQ of both groups (160 \pm 42$)$ was lower compared to other studies, indicating that our population of IBD had a relatively lower quality of life (Table 4).

As it has been shown in other studies, patients with UC scored better in the total and in the four domains of the IBDQ than patients with CD. Between the four domains of the IBDQ, IBD had more impact on patients' social and systemic symptoms when compared to the emotional and bowel symptoms [23]-[25].

In addition when comparing the duration of the disease since diagnosis with the total scores there was no significant difference. Similar result was found in a cohort study conducted in Greece regarding the duration and HRQOL. It was concluded that there was no significant difference when they compared the three groups of duration of the disease and the total score of the HRQOL [25].

\section{Conclusion/Recommendation}

Inflammatory bowel disease has a major impact on patients' HRQOL in different aspects. In our study we found that patients with CD had worse HRQOL compared to UC. The major category to be affected by the disease was the systemic and social domains of the IBDQ. Saudi patients were considered to have a lower QOL compared to other countries. Results showed that IBD significantly affected patients' QOL, which indicated the need and importance of using HRQOL to assess the progression of the disease. The use of IBDQ should be implanted for regular follow up in the clinic to evaluate the response of our management. One of the limitations in the study is 
Table 4. IBDQ scores current study compared to other HRQOL studies.

\begin{tabular}{cccccc}
\hline & Bowel & Systemic & Emotional & Social \\
\hline De Boer et al $(\mathrm{n}=271)$ & $37.3 \pm 7.7^{*}$ & $17.0 \pm 4.4^{*}$ & $44.9 \pm 9.1^{*}$ & $20.0 \pm 4.7$ & $119.1 \pm 22.0^{*}$ \\
Han et al $(\mathrm{n}=30)$ & $54.9 \pm 10.4$ & $25.3 \pm 5.9$ & $64.1 \pm 13.7$ & $29.4 \pm 8.1$ & $173.7 \pm 33.1$ \\
Athansios G et al $(\mathrm{n}=135)$ & $58.9 \pm 10.7$ & $27.7 \pm 6.9$ & $62.4 \pm 15.6$ & $29.1 \pm 7.5$ & $178.1 \pm 36.9$ \\
Current study $(\mathrm{n}=32)$ & $49.6 \pm 13.9$ & $23.0 \pm 7.5$ & $57.4 \pm 19.0$ & $22.9 \pm 9.2$ & $160.3 \pm 42.7$ \\
\hline
\end{tabular}

*Statistical significant at $(\mathrm{p}<0.05)$.

that the study didn't assess the activity of the disease and didn't correlate it with the QOL scores. Another limitation is that the study didn’t include multiple centers.

\section{Conflict of Interest}

The authors declare no potential conflicts of interest in relation to the authorship and/or publication of this article.

\section{References}

[1] Hanauer, S. (2006) Inflammatory Bowel Disease: Epidemiology, Pathogenesis, and Therapeutic Opportunities. Inflammatory Bowel Diseases, 12, S3-S9. http://dx.doi.org/10.1097/01.MIB.0000195385.19268.68

[2] Podolsky, D.K. (2002) Inflammatory Bowel Disease. The New England Journal of Medicine, 347, 417-429. http://dx.doi.org/10.1056/NEJMra020831

[3] Lashner, B. (2009) Inflammatory Bowel Disease. In: Carey, W.D., Ed., Cleveland Clinic: Current Clinical Medicine, Saunders, Philadelphia.

[4] El Mouzan, M., Abdullah, A. and Al Habbal, M. (2006) Epidemiology of Juvenile-Onset Inflammatory Bowel Disease in Central Saudi Arabia. Journal of Tropical Pediatrics, 52, 69-71. http://dx.doi.org/10.1093/tropej/fmi039

[5] Molodecky, N., Soon, I., Rabi, D., Ghali, W., Ferris, M., Chernoff, G., et al. (2012) Increasing Incidence and Prevalence of the Inflammatory Bowel Diseases with Time, Based on Systematic Review. Gastroenterology, 142, 46-54. http://dx.doi.org/10.1053/j.gastro.2011.10.001

[6] De Rooy, E., Toner, B., Maunder, R., Greenberg, G., Baron, D., Steinhart, A., et al. (2001) Concerns of Patients with Inflammatory Bowel Disease: Results from a Clinical Population. The American Journal of Gastroenterology, 96, 1816-1821. http://dx.doi.org/10.1111/j.1572-0241.2001.03877.x

[7] Farmer, R.G., Hawk, W.A. and Turnbull Jr., R.B. (1975) Clinical Patterns in Crohn's Disease: A Statistical Study of 615 Cases. Gastroenterology, 68, 627-635.

[8] Monsén, U., Sorstad, J., Hellers, G. and Johansson, C. (1990) Extracolonic Diagnoses in Ulcerative Colitis: An Epidemiological Study. The American Journal of Gastroenterology, 85, 711-716.

[9] Silverberg, M.S., Satsangi, J., Ahmad, T., Arnott, I.D., Bernstein, C.N., Brant, S.R., et al. (2005) Toward an Integrated Clinical, Molecular and Serological Classification of Inflammatory Bowel Disease: Report of a Working Party of the 2005 Montreal World Congress of Gastroenterology. Canadian Journal of Gastroenterology, 19, 5A-36A.

[10] Bernstein, C., Fried, M., Krabshuis, J., Cohen, H., Eliakim, R., Fedail, S., et al. (2010) World Gastroenterology Organization Practice Guidelines for the Diagnosis and Management of IBD in 2010. Inflammatory Bowel Diseases, 16, 112-124 http://dx.doi.org/10.1002/ibd.21048

[11] Nikolaus, S. and Schreiber, S. (2007) Diagnostics of Inflammatory Bowel Disease. Gastroenterology, 133, $1670-1689$. http://dx.doi.org/10.1053/j.gastro.2007.09.001

[12] Jenkins, D., Balsitis, M., Gallivan, S., et al. (1997) Guidelines for the Initial Biopsy Diagnosis of Suspected Chronic Idiopathic Inflammatory Bowel Disease. The British Society of Gastroenterology Initiative. Journal of Clinical Pathology, 50, 93-105. http://dx.doi.org/10.1136/jcp.50.2.93

[13] Sandborn, W.J., Feagan, B.G. and Lichtenstein, G.R. (2007) Medical Management of Mild to Moderate Crohn’s Disease: Evidence-Based Treatment Algorithms for Induction and Maintenance of Remission. Alimentary Pharmacology \& Therapeutics, 26, 987-1003. http://dx.doi.org/10.1111/j.1365-2036.2007.03455.x

[14] Cima, R.R. and Pemberton, J.H. (2005) Medical and Surgical Management of Chronic Ulcerative Colitis. Archives of Surgery, 140, 300-310. http://dx.doi.org/10.1001/archsurg.140.3.300

[15] Ghosh, S. and Mitchell, R. (2007) Impact of Inflammatory Bowel Disease on Quality of Life: Results of the European Federation of Crohn's and Ulcerative Colitis Associations (EFCCA) Patient Survey. Journal of Crohn's and Colitis, 1, 10-20. http://dx.doi.org/10.1016/j.crohns.2007.06.005 
[16] Graff, L., Walker, J., Lix, L., Clara, I., Rawsthorne, P., Rogala, L., et al. (2006) The Relationship of Inflammatory Bowel Disease Type and Activity to Psychological Functioning and Quality of Life. Clinical Gastroenterology and Hepatology, 4, 1491-1501.e1. http://dx.doi.org/10.1016/j.cgh.2006.09.027

[17] Ramos, A., Calvet, X., Sicilia, B., Vergara, M., Figuerola, A., Motos, J., et al. (2015) IBD-Related Work Disability in the Community: Prevalence, Severity and Predictive Factors. A Cross-Sectional Study. United European Gastroenterology Journal, 3, 335-342. http://dx.doi.org/10.1177/2050640615577532

[18] Irvine, E., Feagan, B., Rochon, J., Archambault, A., Fedorak, R., Groll, A., et al. (1994) Quality of Life: A Valid and Reliable Measure of Therapeutic Efficacy in the Treatment of Inflammatory Bowel Disease. Canadian Crohn's Relapse Prevention Trial Study Group. Gastroenterology, 106, 287-296.

[19] Irvine, E. (1993) Quality of Life-Rationale and Methods for Developing a Disease-Specific Instrument for Inflammatory Bowel Disease. Scandinavian Journal of Gastroenterology, 28, 22-27. http://dx.doi.org/10.3109/00365529309098351

[20] Irvine, E. (1993) Quality of Life-Measurement in Inflammatory Bowel Disease. Scandinavian Journal of Gastroenterology, 28, 36-39. http://dx.doi.org/10.3109/00365529309098355

[21] Loftus, E. (2004) Clinical Epidemiology of Inflammatory Bowel Disease: Incidence, Prevalence, and Environmental Influences. Gastroenterology, 126, 1504-1517. http://dx.doi.org/10.1053/j.gastro.2004.01.063

[22] O’keefe, S. (1996) Nutrition and Gastrointestinal Disease. Scandinavian Journal of Gastroenterology, 31, 52-59.

[23] de Boer, A., Wijker, W., Bartelsman, J. and de Haes, H. (1995) Inflammatory Bowel Disease Questionnaire: CrossCultural Adaptation and further Validation. European Journal of Gastroenterology \& Hepatology, 7, 1043-1050. http://dx.doi.org/10.1097/00042737-199511000-00006

[24] Han, S., McColl, E., Steen, N., Barton, J. and Welfare, M. (1998) The Inflammatory Bowel Disease Questionnaire: A Valid and Reliable Measure in Ulcerative Colitis Patients in the North East of England. Scandinavian Journal of Gastroenterology, 33, 961-966. http://dx.doi.org/10.1080/003655298750026994

[25] Pallis, A., Vlachonikolis, I. and Mouzas, I. (2002) Assessing Health-Related Quality of Life in Patients with Inflammatory Bowel Disease, in Crete, Greece. BMC Gastroenterology, 2, 1. http://dx.doi.org/10.1186/1471-230X-2-1 